Dan Song, Dong Li, Lingyun Qiu

\title{
The Relationship between CIO's Presence in the Top Management Team and IT's Contribution to Corporate Innovation: An Empirical Study
}

\author{
(C) Higher Education Press and Springer-Verlag 2010
}

\begin{abstract}
This study investigates the impact of CIO's presence in an organization's top management team (TMT) on the contribution of information technology (IT) to corporate innovation. A new theoretical model is proposed based on the literature review. Through a survey of 120 CIOs of Chinese companies, we examine a series of hypotheses developed based on this model. Our findings reveal significant influences of CIO's presence in the TMT on IT's contribution to corporate innovations. The findings also suggest that such impacts are mediated by TMT's IT knowledge. Furthermore, we find the significant moderating role of TMT's risk appetite, i.e., when the executives are more willing to take risks, the relationship between CIO's participation in TMT and the importance of IT to innovation is more significant. Theoretical contributions and practical implications of these findings are also discussed.
\end{abstract}

Keywords chief information officer (CIO), top management team (TMT), IT knowledge, risk appetite, corporate innovation

Received March 13, 2010

Dan Song $(\bowtie)$

Guanghua School of Management, Peking University, Beijing 100871, China

E-mail: songdan1@gsm.pku.edu.cn

Dong Li

Guanghua School of Management, Peking University, Beijing 100871, China

E-mail: lidong@gsm.pku.edu.cn

Lingyun Qiu

Guanghua School of Management, Peking University, Beijing 100871, China

E-mail: qiu@gsm.pku.edu.cn 


\section{Introduction}

Along with the economic globalization and technological progress, corporate innovation becomes increasingly important. If an enterprise stays in the rut and cannot adapt to changes through constant innovation, it will fail in fierce competition (Prahalad and Hamel, 1990; Teece, Pisano and Shuen, 1997). In the information era, information technology (IT) not only infiltrates all aspects of the business process, but also has become a part of the products or services, or even an important component (Porter and Millar, 1985). Therefore, for enterprises that hope to become market leaders, they must innovate actively and effectively with the help of IT. Every year, the Information Week magazine selects 500 most innovative companies worldwide. These companies boldly leverage IT to drive corporate innovation, which has improved their competitiveness on existing markets and also created new market opportunities with the application of IT, leading to their great successes (Violino, 1998). In recent years, the Chinese government has also emphasized the importance of taking a new road to industrialization, such as achieving corporate innovation via informationization and so on.

Although many firms have realized the importance of IT-based innovation, in practice IT's contributions to innovation have not received due attention or been given full play. Despite being a leading figure in companies, only a few of CIOs can make effective use of IT to innovate. In 2008, a survey of China's CIOs showed that their top concerns were mainly on how to provide their companies better information services rather than making use of IT to innovate (CIO Insight, 2008). While this problem has been recognized by prior research (Swanson, 1994; Armstrong and Sambamurthy, 1999; Lind and Zmud, 1991), there is no widely accepted theory, and in-depth empirical research on this issue is also absent. This paper proposes a new theoretical model on this issue and conducts a survey to test the hypotheses empirically.

To examine the factors that affect and drive IT-based corporate innovation, this study adopts the perspective of the behaviors and cognition of both the CIOs and the company's top management team (TMT) (Offstein, Gnyawali and Cobb, 2005; Nahapiet and Ghoshal, 1998). We find that three factors affect the use of IT in corporate innovation. First, TMT's awareness of the importance of IT to innovation is the decisive factor. TMT has decision-making power, and its members are not aware of IT's contributions to innovation, it is often difficult for IT to enter innovation related decision-making agenda. Secondly, a CIO also plays an important part in enhancing IT's contributions to innovation. If a CIO is a member of TMT or can properly let TMT members know the importance of IT, he/she can promote the enterprise's IT-based innovation. Finally, as IT-based innovations often involve huge investment, therefore, TMT's risk appetite also 
has much impact on this.

The next section proposes the theoretical model and hypotheses with the support of theoretical analysis and literature review. The research method is then introduced in Section 2. Section 3 analyzes the empirical results and Section 4 summarizes the contributions and limitations of this study, as well as suggestions for future study.

\section{Literature Review and Research Hypotheses}

2.1 The Relationship between CIO's Presence in TMT and IT's Contributions to Innovation

Innovation is defined by Becker and Whisler (1967: 463) as "the first or early use of an idea by one of a set of organizations with similar goals." It is also defined as an organization's adoption of a new idea or behavior. Even if this idea is nothing new to other organizations, as long as the organization that adopts it has not used it before, it can be considered as an innovation (Mohr, 1969). An organization's innovation has a variety of forms. Evan (1966) divided innovation into technology innovation and management innovation. Robey (1986) categorized innovation into new products (or services), management innovation and technology innovation. Zmud (1982) classified innovation into innovation of product or service and innovation of business process. Among the studies of innovation, the process school believes that innovation is a process for people within an organization to generate and/or adopt a new idea or a new method through interactions (Lu and Liang, 2009). For example, Daft (1978) divided innovation into four steps: forming an innovative idea, proposing the idea, decision-making on the adoption, and implementation. In the literature review, Pierce and Delbecq mentioned that the three-stage model of Thompson (1965) is the most representative, which includes the initiation, adoption and implementation of an idea (Pierce and Delbecq, 1977).

This paper mainly adopts the viewpoint of Zmud (1982), believing that IT's importance to innovation is equivalent to IT's importance to an enterprise's innovation of product or service and process. Innovation of product or service refers to offerings of new products or services through the introduction of IT, so as to deliver new value to customers. For example, hi-tech firms like Apple combine IT and audio-visual products; and garment firms integrate RFID with products and services. Innovation of process mainly refers to bringing in IT to change the methods, processes or responsibilities in the traditional business process so as to enhance work efficiency or effectiveness. For example, the aviation industry integrates IT with the ticket selling process, leading to significant cost saving and improved efficiency. 
CIO's presence in TMT can facilitate the integration of IT knowledge and business knowledge. In order to create innovative ideas, firms need to integrate different knowledge and produce new knowledge (Lu and Liang, 2009). In order to bring into full play IT's contributions to innovation, organizations need to integrate IT knowledge and business knowledge. TMT can be seen as an organizational structure that integrates member knowledge for sharing of views, pooling of knowledge and formation of a common understanding (West and Anderson, 1996; MacCurtain, Flood, Ramamoorthy, West and Dawson, 2008). If a CIO becomes a member of TMT, he/she can obviously play an important role in providing IT knowledge and promoting the integration of IT knowledge and business knowledge in TMT activities. For example, at TMT's regular meetings, CIO can often introduce the benefits and opportunities that IT brings to the development of the organization. Such exchanges will enable all TMT members to fully understand the status quo and development trend of IT, inspire new ideas from top managers, and promote the generation of new ideas, new technologies and new methods, thus providing the driving force for the organization's IT-based innovation.

CIO's presence in TMT will also help the CIO enhance his/her business abilities. IT managers are required to be technologically competent, and their business abilities are also considered an important factor in the performance of IT work, and the difference of such capacity among CIOs is far more greater than that of technological capabilities, so it is also an important reason for the difference of IT performance among different corporations (Ross, Beath and Goodhue, 1996; Earl and Feeny, 1994). CIOs with a deep understanding of the business will consider IT application from the business perspective and put forward the idea of IT-based corporate innovation. CIO's presence in TMT can also enrich the CIO's business knowledge and improve his/her business abilities. When the CIO attends meetings of top managers as a member of the TMT, he/she can timely access the latest business knowledge, and establish a deep understanding of the focus of the organizational strategy (Armstrong and Sambamurthy, 1999).

CIO's presence in TMT is also beneficial to the collaboration between CIO and TMT. Compared with other operations, effective completion of IT projects needs a closer collaboration with other departments, so the collaborative relationship between a CIO and other managers determines the success or failure of IT work (Ross, Beath and Goodhue, 1996). In order to reach an agreement with other departments and establish a sound partnership, the communication between the CIO and other managers is very important. CIO's presence in TMT provides a platform for communication between the $\mathrm{CIO}$ and other managers. Through a lot of communications, the CIO and other top managers can reach consensus more easily on the opportunities of IT-based innovation, and build 
good relations of mutual trust and mutual support (Feeny and Edwards, 1992).

Prior studies have also put forward and supported the views mentioned above. Lind and Zmud (1991) found that the sufficient interactions between technological and business managers improved the level of IT-based innovation. Mata, Fuerst and Barney (1995) proposed the key of the effective use of IT lies in the integration of the business and IT knowledge through interactions within an organization. According to Cohen and Levinthal's theory of absorptive capacity, the integrated knowledge of business and IT and the new knowledge of IT-based innovation gained through learning reflect TMT's absorptive capacity (Cohen and Levinthal, 1990). In their study, Smaltz, Sambamurthy and Agarwal (2006) also revealed the importance of CIO's presence in TMT. Based on the above analysis, we put forward Hypothesis 1:

H1 CIO's presence in TMT positively affects IT's contributions to innovation.

\subsection{The Mediating Role of Top Managers' IT Knowledge}

Top business managers play an irreplaceable role in the use of IT in an enterprise. In any organization, key IT users are line managers of various functions, operations, and geographical regions. They are the ones who are most familiar with their businesses, and know how to use IT resources to support corporate strategy most effectively. Line managers can provide the direction of the strategy and tactics, and, during the implementation, promise financial support and promise to change the new system's objective to an improved organizational process (Rockart, Earl and Ross, 1996). Therefore, top business managers and line managers are important sources for innovation with the use of IT (Boynton and Zmud, 1994; Rockart, 1988). Among the top 500 companies picked by the Information Week, many IT managers emphasized that they got most ideas on innovative use of IT from their business managers and users. They think that the real drive for a project comes from the business needs. Innovation is everyone's responsibility, and we must rely on the entire company instead of the IT department only to put forwards a good idea on the best application of IT (Violino, 1998).

In order to bring into play its role in IT work, top managers must have the necessary IT knowledge. Previous studies have showed that TMT's IT knowledge is the key to IT success (Kearns and Sabherwal, 2006; Bassellier, Benbasat and Reich, 2003; Davis, Kettinger and Kunev, 2009; Brown, Chervany and Reinicke, 2007). As Rockart et al. (1996: 53) put it, "the success or failure of an organizations use of IT, however, is only partially dependent on the effectiveness of the IT organization. It is even more dependent on the capability of line managers at all levels to understand the capabilities of the IT resource and 
to use it effectively." If TMT does not have the necessary IT knowledge, it tends to pass the responsibility of important IT decision-making to CIO or IT department, and in this way TMT would be unable to play its irreplaceable role and thus negatively affects the effective use of IT. Bassellier et al. (2003) have also found that business managers' IT knowledge and IT experience will influence their enthusiasm for championing IT projects.

Top managers' understanding of IT knowledge is often directly associated with CIO's presence in TMT. For top managers, frequent communication with CIO is their major access to IT knowledge (Armstrong and Sambamurthy, 1999). Though top managers can also gain IT knowledge from other sources, the education by and influence of $\mathrm{CIO}$ is closer to the enterprise's own characteristics, and therefore, is more easily understood and accepted by top managers. Based on the above analysis, we propose the following two hypotheses:

H2 Top managers' IT knowledge positively affects IT's contributions to innovation.

H3 Top managers' IT knowledge mediates the impacts of CIO's presence in TMT on IT's contribution to corporate innovation.

\subsection{The Moderating Role of Top Managers' Risk Appetite}

IT's contributions to corporate innovation have something to do with the characteristics of TMT itself. In addition to risks associated with doing something new, heavy IT investments and many cases of IT project failures all illustrate the uncertainty and risks involved in the application of IT. Scholars studying the relationship between culture and information system have pointed out that uncertainty avoidance cultures is important to the organization's decision-making on IT adoption and diffusion. Due to IT's inherent risk, it is less possible for firms that dislike uncertainty to adopt and use new technology (Leidner and Kayworth, 2006). In his study of corporate culture, Wallach (1983) identified an innovative culture that emphasizes taking more challenges and risks, and firms with such a cultural characteristic are more likely to innovate. Thus, TMT's risk appetite can affect the enterprise's decision-making for IT-based innovation. CIO's presence in TMT can help top managers realize the potential opportunities for IT-based innovation, but only if they are willing to take risks, they are likely to implement innovative ideas; or, when top managers do not want to take the risks of innovation, IT will not help innovation. Based on the above analysis, we put forward Hypothesis 4 as below:

H4 Top managers' risk appetite plays a moderating role in the relationship between CIO's presence in TMT and IT's contribution to innovation: When executives are more willing to take risks, the relationship between CIO's 
presence in TMT and IT's contribution to innovation is more significant.

Based on the above-mentioned four hypotheses, the theoretical model of this study is shown in Fig. 1:

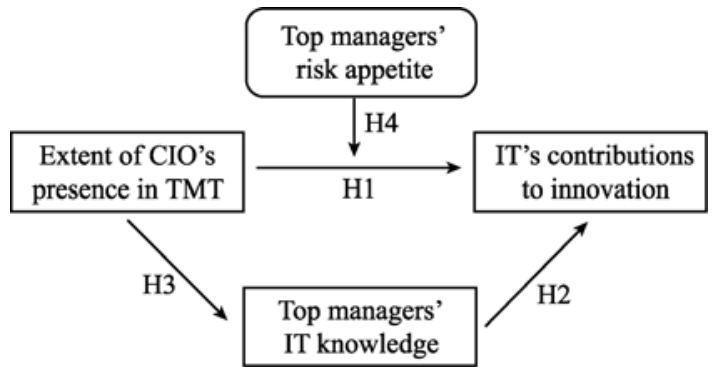

Fig. 1 The Theoretical Model

\section{Research Method}

\subsection{Sample Collection}

This study used the survey method and the data were mainly collected from corporate CIOs or top IT managers. Sampled firms came from the database of China's CIOs provided by an industry magazine. The database is designed to make a systematical study of China's CIOs, and its samples have carefully selected out from China's CIOs after a multi-dimensional investigation of industry, size, geography, property rights, and influence. This study randomly picked 500 respondents from the database, and via a questionnaire survey, 150 were returned with a response rate of $30 \%$. Excluding responses with missing items, there were altogether 120 valid responses.

\subsection{Measurement Scales}

IT's contributions to innovation. According to the classification of IT innovation by Zmud (1982), IT's contributions to innovation can be measured from three aspects-its importance to the innovations of products, services and process. This paper adopted the five-point Likert-type scale, and according to actual situation of the firms, the respondents selected IT's degree of importance to an enterprise's different types of innovation from 1-5 that represents a range from "very unimportant" to "very important."

CIO's presence in TMT. Based on the reference to relevant study conducted by Armstrong and Sambamurthy (1999): The "CIO's presence in TMT" was measured with categorical variables. The questionnaire provided three types of CIO's presence in an enterprise's strategic decision-making, namely "as a 
member of TMT," "as a technological consultant," and "little presence or almost no presence." The respondents selected the best answer in line with the actual situation of their firm.

Top managers' IT knowledge. This study mainly measured top managers' strategic IT knowledge, and did not include specific IT knowledge related to IT activities. Items measuring the strategic IT knowledge were adopted from scales used by Armstrong and Sambamurthy (1999) and Kearns and Sabherwal (2006), including the extent of familiarity with the existing information systems, with other information systems that might be used, and with competitors' information systems. Each item was measured by a five-point Likert-type scale, with the answers ranging from "totally disagree" to "completely agree."

Top managers' risk appetite. Based on Benaroch (2002), this study measured top managers' risk appetite from three aspects, i.e., organizational risks brought about by major changes of organizational structure, technological risks due to the adoption of new technology, hardware and software that the enterprise is unfamiliar with, and financial risks caused by new systems and other major investments. Each question was measured by a five-point Likert-type scale, with the answers ranging from "totally disagree" to "completely agree."

\section{Data Analysis and Hypothesis Test}

\subsection{Descriptive Statistics}

As shown in Table 1, firms surveyed came from a wide range of industries, particularly from the manufacturing and financial and securities industries (amounting to $24.1 \%$ and $18.1 \%$, respectively). In terms of corporate ownership, nearly half $(49.6 \%)$ of the sample were state-controlled (or state-owned), reflecting one of the typical characteristics of Chinese corporations (See Table 2). As for the respondents' presence in TMT, the most common answer was "as a technological consultant" and the fewest was "very little presence or almost no presence." These two categories combined account for $70.8 \%$, much bigger than the proportion of those who served "as a member of TMT," implying a low level of Chinese CIO's presence in TMT (Table 3).

\subsection{Validity Test}

In order to test the internal consistency of the three variables, namely IT's contribution to innovation, TMT's knowledge of IT and TMT's risk appetite, we calculated their Cronbach's $\alpha$, which are $0.71,0.82$, and 0.78 respectively. As they are all above 0.7 , we deem these scales' internal reliability acceptable. 
Table 1 Distribution of Sample Enterprises by Industries

\begin{tabular}{lcc}
\hline \multicolumn{1}{c}{ Industry } & Number & Percentage \\
\hline Manufacturing & 28 & $24.1 \%$ \\
Construction \& real estate & 4 & $3.3 \%$ \\
Wholesale and retail & 9 & $7.8 \%$ \\
Public utilities & 3 & $2.6 \%$ \\
Transportation and warehousing & 7 & $6.0 \%$ \\
Government departments & 7 & $6.0 \%$ \\
Social services (e.g., science, education) & 9 & $7.8 \%$ \\
Financial \& securities & 21 & $18.1 \%$ \\
Telecommunications & 4 & $3.4 \%$ \\
Software and information services & 7 & $6.0 \%$ \\
Media (publishing/broadcast/advertising/PR) & 5 & $4.3 \%$ \\
Others & 12 & $10.3 \%$ \\
\hline
\end{tabular}

Table 2 Distribution of Sample Enterprises by Corporate Nature

\begin{tabular}{lcc}
\hline \multicolumn{1}{c}{ Corporate nature } & Number & Percentage \\
\hline State-owned (or state-controlled) enterprises & 59 & $49.6 \%$ \\
Private enterprises & 18 & $15.1 \%$ \\
Foreign-owned enterprises & 8 & $6.7 \%$ \\
Foreign joint ventures & 7 & $5.9 \%$ \\
Government departments or institutions & 23 & $19.3 \%$ \\
Others & 4 & $3.3 \%$ \\
\hline
\end{tabular}

Table 3 CIO's Presence in TMT

\begin{tabular}{lcc}
\hline \multicolumn{1}{c}{ CIO's presence in TMT } & Number & Percentage \\
\hline As a member of TMT & 35 & $29.2 \%$ \\
As a technological consultant & 72 & $60.0 \%$ \\
Little presence or almost no presence & 13 & $10.8 \%$ \\
\hline
\end{tabular}

Table 4 Variable Description and Their Correlation

\begin{tabular}{lccccc}
\hline & Mean & $\begin{array}{c}\text { Standard } \\
\text { deviation }\end{array}$ & 1 & 2 & 3 \\
\hline $\begin{array}{l}\text { 1. Importance of IT to } \\
\text { innovation }\end{array}$ & 3.5333 & 0.93824 & 1 & & \\
$\begin{array}{l}\text { 2. Top managers' IT } \\
\text { knowledge }\end{array}$ & 3.0667 & 0.98029 & $0.315^{* *}$ & 1 & \\
$\begin{array}{l}\text { 3. Top managers' risk } \\
\text { appetite }\end{array}$ & 2.9944 & 0.96820 & $0.284^{* *}$ & $0.472^{* *}$ & 1 \\
\hline
\end{tabular}

Note: ** indicates significant at 0.01 level (two-tailed). 
We then employed exploratory factor analysis to test discriminant and convergent validity. As there are three items for each construct, we have a total of nine items. Using principal components analysis method, we found three factors' eigenvalues are greater than one. In the rotated component matrix using varimax, the three items of each construct have greater loading on their own factor (see Table 5 and 6), indicating that the scales of the three constructs have good discriminant and convergent validity.

Table 5 Principal Component Analysis Result

\begin{tabular}{cccc}
\hline Principal component & Eigenvalue & Percentage (\%) & Cumulative (\%) \\
\hline 1 & $\mathbf{3 . 6 2 9}$ & $\mathbf{4 0 . 3 1 9}$ & $\mathbf{4 0 . 3 1 9}$ \\
2 & $\mathbf{1 . 5 0 9}$ & $\mathbf{1 6 . 7 7 2}$ & $\mathbf{5 7 . 0 9 1}$ \\
3 & $\mathbf{1 . 1 4 5}$ & $\mathbf{1 2 . 7 2 7}$ & $\mathbf{6 9 . 8 1 8}$ \\
4 & 0.723 & 8.033 & 77.851 \\
5 & 0.634 & 7.039 & 84.890 \\
6 & 0.479 & 5.323 & 90.213 \\
7 & 0.384 & 4.270 & 94.483 \\
8 & 0.276 & 3.065 & 97.548 \\
9 & 0.221 & 2.452 & 100.000 \\
\hline
\end{tabular}

Table 6 Rotated Component Matrix

\begin{tabular}{lccc}
\hline & & Principal component & \\
\hline & 1 & 2 & 3 \\
Product innovation & 0.140 & 0.061 & $\mathbf{0 . 7 6 1}$ \\
Service innovation & 0.059 & 0.075 & $\mathbf{0 . 8 8 8}$ \\
Business process innovation & 0.140 & 0.134 & $\mathbf{0 . 6 9 0}$ \\
TMT's knowledge about IS (1) & $\mathbf{0 . 8 2 0}$ & 0.227 & 0.070 \\
TMT's knowledge about IS (2) & $\mathbf{0 . 8 1 3}$ & 0.214 & 0.253 \\
TMT's knowledge about IS (3) & $\mathbf{0 . 8 3 9}$ & 0.140 & 0.095 \\
TMT's risk preference 1 & 0.167 & $\mathbf{0 . 7 7 9}$ & -0.035 \\
TMT's risk preference 2 & 0.306 & $\mathbf{0 . 7 4 2}$ & 0.262 \\
TMT's risk preference 3 & 0.135 & $\mathbf{0 . 8 6 5}$ & 0.149 \\
\hline
\end{tabular}

We next examined whether or not common method variance was a serious problem in this study. This study's main independent variable (CIO's extent of presence in TMT) is a categorical variable. In addition, as the questionnaire used in this study includes several parts for measurement purpose. (i.e., "top managers' IT knowledge" and "top managers' risk appetite" were in Part 3, while "IT's contributions to innovation" was in Part 8), measuring the distance between these measurements would reduce variance (Zhou and Long, 2004). We 
conducted Harman's one-factor test in two different ways to examine whether common method variance is a serious issue (Podsakoff and Organ, 1986). First, the 9 items measuring three constructs were entered into an exploratory factor analysis, and the results revealed that there are three distinct factors with eigenvalue greater than 1.0 and no single factor is able to explain a majority of the variance in the variables. Moreover, we loaded all variables on one factor to examine the fit of the confirmatory factor analysis model. Again, results showed that the single-factor model did not fit the data well $(\mathrm{NNFI}=0.65$; CFI $=0.74$; RMSEA $=0.20$ ). While the results of these analyses do not preclude the possibility of common method bias, they do suggest that the bias is not of great concern in this study and thus is unlikely to confound the interpretation of our results.

\subsection{Hypothesis Test}

We used linear regression to test $\mathrm{H} 1-\mathrm{H} 4$. To do this, the categorical variable of "CIO's presence in TMT" needs to be converted. We therefore converted this variable into three dummy variables: $d a, d b$ and $d c$. $d a$ takes the value of 1 if CIO is "a member of TMT," and 0 otherwise. $d b$ is 1 if CIO works "as a technological consultant," and 0 otherwise. $d c$ is 1 when CIO has "little presence or almost no presence," and 0 otherwise.

\subsubsection{Testing of $\mathrm{H} 1$}

Since the linear regression model has an intercept, we only need to enter into the model any two of the three dummy variables, and use the third one as baseline category. Dummy variable's regression coefficient indicates the magnitude, direction and significance of the difference between this variable's mean and the baseline category's mean. First we took $d a$ and $d b$ as independent variables to conduct the simple linear regression analysis. The results in Table 7 show that $d a$ 's coefficient is significantly different from zero, and $d b$ 's coefficient has a lower level of significance. These results suggest that "as a member of TMT" sample group's mean is significantly higher than that of "little or almost no presence" group; but the difference between "as a technological consultant" sample group and "little or almost no presence" sample group is not significant. To further explore the mean's difference between the "as a member of TMT" group and the "as a technological consultant" group, we put "as a member of TMT" group as baseline, and carried out the regression with $d b$ and $d c$ as independent variables. In Table 7, $d b$ and $d c$ 's coefficients shown in column Model 2 are both significant, indicating that the mean of "as a member of TMT" sample group is significantly higher than either of the other two sample groups. 
By using analysis of variance (ANOVA), same conclusion can be drawn that, concerning the dependent variable- "IT's contribution to innovation," the "as a member of TMT" group is significantly higher than either the "as a technological consultant" group $(p<0.05)$ or the "little presence or almost no presence" $(p<$ 0.01 ) group; and the difference between the latter two groups is not significant ( $p$ $=0.08)$. $\mathrm{H} 1$ is supported.

Table 7 Impacts of "CIO's Presence in TMT" on "IT's Contribution to Innovation"

\begin{tabular}{ccc}
\hline & Model1 & Model2 \\
\hline$d a$ & $0.930^{* *}$ & \\
$d b$ & $0.479^{\wedge}$ & $-0.451^{*}$ \\
$d c$ & & $-0.930^{* *}$ \\
$F$ & $5.731^{* *}$ & $5.731^{* *}$ \\
$R^{2}$ & 0.089 & 0.089 \\
\hline
\end{tabular}

Note: Dependant variable is "IT's contribution to innovation";

Coefficient of independent variable is unstandardized;

** denotes significant at 0.01 level, $*$ denotes significant at 0.05 level, $\wedge$ denotes significant at 0.1 level.

\subsubsection{Testing of $\mathrm{H} 2$ and $\mathrm{H} 3$}

To test the mediating role of top executives' IT knowledge, we compared the results of four regression models: Model 2 ("CIO's extent of presence in TMT" on "IT's contribution to innovation"), Model3 ("top managers' IT knowledge" on "IT's contribution to Innovation"), Model 4 ("CIO's extent of presence in TMT" on "top managers' IT knowledge") and Model 5 ("CIO's extent of presence in TMT" and "Top managers' IT knowledge" on "IT's contribution to innovation"). Table 8 compares the analysis results of these four models. The regression results of Model 3 show that the coefficient of variable "top managers' IT knowledge" has a high level of significance, indicating that top executives' IT knowledge has a positive impact on IT's contribution to innovation. H2 is supported. Analysis result of Model 4 shows, in comparison with "as a member of TMT" group, the other two groups have significantly lower means in terms of "top managers' IT knowledge." Model 5's results indicate that, when regressing $d b, d c$ and "top executives' IT knowledge" concurrently on "IT's contribution to innovation," the significances of $d b$ and $d c$ 's coefficients decrease, as well as the two coefficients' absolute values. This shows that, once "top executives' IT knowledge" is controlled, the direct impact of "CIO's extent of presence in TMT" on "IT's contribution to innovation" decreases significantly, and part of the impact is exerted indirectly through top executives' IT knowledge. H3 is also supported. 
Table 8 “Top executives' IT knowledge" as a Mediator

\begin{tabular}{lcccc}
\hline & Model 2 & Model 3 & Model 4 & Model 5 \\
\hline$d b$ & $-0.451^{*}$ & & $-0.390^{*}$ & $-0.355^{\wedge}$ \\
$d c$ & $-0.930^{* *}$ & & $-0.826^{* *}$ & $-0.728^{*}$ \\
Top Managers' IT knowledge & & $0.302^{* *}$ & & $0.245^{* *}$ \\
$F$ & $5.731^{* *}$ & $13.027^{* *}$ & $3.973^{*}$ & $6.863^{* *}$ \\
$R^{2}$ & 0.089 & 0.099 & 0.064 & 0.151 \\
\hline
\end{tabular}

Note: In Model 4, the dependent variable is "top executives' IT knowledge," while in other models, the dependent variable is "IT's contribution to innovation";

Coefficient of independent variable is unstandardized;

** denotes significant at 0.01 level, * significant at 0.05 level, ^ significant at 0.1 level.

\subsubsection{Testing of $\mathrm{H} 4$}

We add an interaction term in regression analysis so as to verify the moderation effect of "top executives' risk preference." To maintain the model's stability, $d b$, $d c$ and "top managers' risk appetite" are centralized. Model 8's result in Table 9 shows that the product of centralized $d b$ and centralized "top managers' risk appetite", namely, centerdb*centerrisk, has a significant coefficient, demonstrating the difference between the mean of "as a member of TMT" group and that of "as a technological consultant" group varies with top manager's risk appetite- The higher the risk appetite is, the bigger the difference will be. The product of centralized $d c$ and centralized "top managers' risk appetite"

Table 9 "Top managers' risk appetite" as a moderator ${ }^{1}$

\begin{tabular}{lcccc}
\hline & Model2 & Model 6 & Model 7 & Model 8 \\
\hline centerdb & $-0.451^{*}$ & & $-0.355^{\wedge}$ & -0.297 \\
centerdc & $-0.930^{* *}$ & & $-0.746^{*}$ & -0.454 \\
centerrisk & & $0.275^{* *}$ & $0.211^{*}$ & $0.193^{*}$ \\
centerdb $\times$ centerrisk & & & $-0.418^{*}$ \\
centerdc $\times$ centerrisk & & & & 0.215 \\
$F$ & $5.731^{* *}$ & $10.344^{* *}$ & $5.932^{*}$ & $5.333^{* *}$ \\
$R^{2}$ & 0.089 & 0.081 & 0.133 & 0.190 \\
\hline
\end{tabular}

Note: Dependent variable in the models is "IT's contribution to innovation"; centerdb, centerdc and centerrisk denote centralized " $d b$," centralized " $d c$ " and centralized "Top managers' risk appetite", respectively; Coefficient of independent variable is unstandardized; ** denotes significant at 0.01 level, $*$ denotes significant at 0.05 level, $\wedge$ denotes significant at 0.1 level.

${ }^{1}$ Although the $R^{2}$ value in our regression analysis is relatively small, this is not unusual, especially when the number of independent variables is limited. Similar results were also reported in previous studies, such as Lind and Zmud (1991) and Lu and Liang (2009). 
(centerd $c^{*}$ centerrisk) has an insignificant coefficient. This might be attributed to the reason that we have such a small population in "little or almost no presence" group so that the variation is not reflected. According to the above analysis, $\mathrm{H} 4$ is partly supported.

\section{Discussion}

This research mainly analyzes how CIO's presence in TMT affects IT's contribution to innovation. After analysis of surveyed data, the following findings are obtained:

(1) In comparison with "as a technological consultant" and "little or almost no presence," CIO's presence in corporate strategic decision making as a formal member of TMT will have IT contributed the most to a company's innovation.

(2) Top executives' IT knowledge has a significant impact on IT's contribution to innovation. The more IT knowledge the top executives have, the bigger IT contributes to the enterprise's innovation.

(3) CIO's extent of presence in TMT significantly influences top executives' IT knowledge. When CIO is involved in corporate strategic decision-making as a formal member of TMT, top managers can master more IT knowledge.

(4) The influence of "CIO's extent of presence in TMT" on "IT's contribution to innovation" is partly exerted through top managers' IT knowledge.

(5) Top managers' risk appetite has an impact on the relationship between CIO's extent of presence in TMT and IT's contribution to innovation. Only if top managers is willing to take the risk of IT operations, can CIO's presence in TMT promote IT's innovation role in an easier way.

This paper empirically explores, for the first time, the relationship between CIO's presence in the top management team and IT's contribution to corporate innovation. It therefore can help Chinese companies gain a deeper understanding of IT's contribution to corporate innovation. The paper not only analyzes how CIO, as a formal member of TMT, positively influences IT's contribution to innovation, but also discusses about the scenarios where top managers' IT knowledge and risk appetite are taken as mediator and moderator, thus enriches the relevant theory.

This paper theoretically illustrates the importance to promote CIO's (or IT manager's) status in an enterprise. In order to make full use of IT, an enterprise should actively push for CIO's formal membership in TMT, and strengthen CIO's communication with other executives. In order to realize this, not only CIO should constantly learn about a company's business knowledge, but it's also essential for top managers to gain a deeper understanding of IT, and their knowledge sharing will greatly enhance IT's contributions to corporate innovation. Finally, firms should be aware that TMT's characteristics affect IT's 
contributions to innovation, and TMT's continuous updating of its own knowledge structure and cultivation of its innovativeness is significant to the effective application of new technology.

Limitations of this research should also be noted. Due to the constraints in data collection, questionnaires were completed by CIOs or IT managers, rather than by other top managers. This may lead to personal subjective bias in their answers. Also, the data we used are cross-sectional by nature, so the causal-effect relationship cannot be extracted simply from the correlations among variables, and the impact from some other variable could not be ruled out either.

The following suggestions are offered for future work: (1) Try to find a better measurement for the communication and interaction between CIO and TMT; (2) find a better approach to measuring and comparing IT's application level in firms; (3) identify other factors that might influence IT's contribution to innovation. For example, even if a CIO is a member in TMT and exerts impact on corporate innovation, such an impact might be moderated by the CIO's capability. Future studies also need to explore other mechanisms for promoting communication, decision making and IT responsibility sharing when the CIO is not a member of TMT; (4) Lastly, the potential impact of other characteristics of TMT other than risk preference on IT's innovation role shall also be discussed in future study.

Acknowledgements This project is supported by the National Natural Science Foundation of China (No. 70928001).

\section{References}

Armstrong C P, Sambamurthy V (1999). Information technology assimilation in firms: The influence of senior leadership and IT infrastructures. Information Systems Research, 10(4): 304-327

Bassellier G, Benbasat I, Reich B H (2003). The influence of business managers' IT competence on championing IT. Information Systems Research, 14(4): 317-336

Becker S W, Whisler T L (1967). The innovation organization: A selective view of current theory and research. Journal of Business, 40: 462-469

Benaroch M (2002). Managing information technology investment risk: A real options perspective. Journal of Management Information Systems, 19(2): 43-84

Boynton A C, Zmud R W, Jacobs G (1994). The influence of IT management practices on IT use in large organizations. MIS Quarterly, 18: 299-318

Brown S A, Chervany N L, Reinicke B A (2007). What matters when introducing new information technology. Communications of the ACM, 50(9): 91-96

CIO Insight 研究中心, 北京大学光华管理学院 (CIO Insight Research Center, Guanghua School of Management of Peking University) (2008). 2008 年度中国 CIO1000 调研报告 (The annual report of Chinese CIO 1000). 信息方略, (25): 34-57

Cohen W M, Levinthal D A (1990). Absorptive capacity: A new perspective on learning and innovation. Administrative Science Quarterly, 35: 128-152 
Daft R L (1978). A dual-core model of organizational innovation. Academy of Management Journal, 21: 193-210

Davis J M, Kettinger W J, Kunev D G (2009). When users are IT experts too: The effects of joint IT competence and partnership on satisfaction with enterprise-level systems implementation. European Journal of Information Systems, 18: 26-37

Earl M J, Feeny D F (1994). Is your CIO adding value? Sloan Management Review, 35(3): $11-20$

Evan W M (1966). Organizational lag. Human Organization, 25: 51-53

Feeny D F, Edwards B R, Simpson K M (1992). Understanding the CEO/CIO relationship. MIS Quarterly, 16: 435-448

Kearns G S, Sabherwal R (2006). Strategic alignment between business and information technology: A knowledge-based view of behaviors, outcome, and consequences. Journal of Management Information Systems, 23(3): 129-162

Leidner D E, Kayworth T (2006). Review: A review of culture in information systems research: Toward a theory of information technology culture conflict. MIS Quarterly, 30(2): 357-399

Lind M, Zmud R W (1991). The influence of a convergence in understanding between technology providers and users on information technology innovativeness. Organization Science, 2: 195-217

MacCurtain S, Flood P C, Ramamoorthy N, West M A, Dawson J F (2008). Top team trust, knowledge sharing and innovation. LINK Working Paper Series. http://doras.dcu.ie/2420/

Mata F J, Fuerst W L, Barney J B (1995). Information technology and sustained competitive advantage: A resource-based analysis. MIS Quarterly, 19(4): 487-506

Mohr L B (1969). Determinants of innovation in organizations. American Political Science Review, 63: 111-126

Nahapiet J, Ghoshal S (1998). Social capital, intellectual capital, and the organizational advantage. Academy Management Review, 23(2): 242-266

Offstein E H, Gnyawali D R, Cobb A T (2005). A strategic human resource perspective of firm competitive behavior. Human Resource Management Review, 15: 305-318

Pierce J L, Delbecq A L (1977). Organization structure, individual attitudes and innovation. Academy of Management Review, 2: 27-37

Podsakoff P M, Organ D W (1986). Self-reports in organizational research: Problems and prospects. Journal of Management, 12(4): 531-544

Porter M E, Millar V E (1985). How information gives you competitive advantage. Harvard Business Review, 63(4): 149-160

Prahalad C K, Hamel G (1990). The core competence of the corporation. Harvard Business Review, 66(3): 71-91

Robey D (1986). Designing Organizations. Homewood, IL: Irwin

Rockart J F (1988). The line takes the leadership: IS management in the wired society. Sloan Management Review, 29(4): 57-64

Rockart J F, Earl M J, Ross J W (1996). Eight imperatives for the new IT organization. Sloan Management Review, 38(1): 43-55

Ross J W, Beath C M, Goodhue D L (1996). Develop long-term competitiveness through IT assets. Sloan Management Review, 38(1): 31-42

Smaltz D H, Sambamurthy V, Agarwal R (2006). The antecedents of CIO role effectiveness in organizations: An empirical study in the healthcare sector. IEEE Transactions on Engineering Management, 53(2): 207-222

Swanson E B (1994). Information systems innovation among organizations. Management Science, 40(9): 1069-1092 
Teece D J, Pisano G, Shuen A (1997). Dynamic capabilities and strategic management. Strategic Management Journal, 18(7): 509-533

Thompson V A (1965). Bureaucracy and innovation. Administrative Science Quarterly, 10: $1-20$

Violino B (1998). Defining IT innovation. InformationWeek, 14: 58

Wallach E J (1983). Individuals and organizations: The cultural match. Training and Development Journal, 37(2): 28-35

West M A, Anderson N R (1996). Innovation in top management teams. Journal of Applied Psychology, 81(6): 680-694

Zhou H, Long L R (2004). Statistical remedies for common method biases. Advances in Psychological Science, 12(6): 942-950

Zmud R W (1982). Diffusion of modern software practices: Influence of centralization and formalization. Management Science, 28(12): 1421-1431

路琳, 梁学玲 (Lu Lin, Liang Xueling) (2009). 知识共享在人际互动与创新之间的中介作 用研究 (The mediating effect of knowledge sharing between interpersonal interactions and innovation). 南开管理评论, 12(1): 118-123 